\title{
Frequency of chronic diseases in elderly age group.
}

1. Final Year MBBS Student Fatima Memorial College of Medicine \&

Dentistry, Shadman, Lahore. 2. MBBS,

MCPS (Community Medicine) Assistant Professor Community Medicine

Fatima Memorial College of Medicine \& Dentistry, Shadman, Lahore.

3. Final Year MBBS Student Fatima Memorial College of Medicine \& Dentistry, Shadman, Lahore.

Correspondence Address:

Dr. Shamaila Hassnain

Department of Community Medicine

Fatima Memorial College of Medicine

\& Dentistry,

Shadman, Lahore. Pakistan.

sash04@yahoo.com

Article received on:

27/07/2020

Accepted for publication:

$18 / 11 / 2020$

\begin{abstract}
Arslan Mir ${ }^{1}$, Shamaila Hassnain ${ }^{2}$, Anas Khan ${ }^{3}$
ABSTRACT... Objective: To determine the frequency of chronic diseases in elder age group of above 60 years along with their regular activities and functional limitations. Study Design: Cross Sectional study. Setting: Thokar Niaz Baig Area of Lahore. Period: January 2017 to June 2017. Material \& Methods: A total of 163 respondents, both males and females above the age of 60 years were interviewed using Quota sampling. Data was collected with the help of a pretested structured questionnaire after informed consent. Results: The mean age of our study sample was $69 \pm 7.1$ years. $63.8 \%$ were males while females were only $36.2 \%$. Hypertension was found to be $69.3 \%$ followed by Diabetes in $51.5 \%$, Visual disturbance $52.1 \%$. Only $10.4 \%$ were dependent in physical activity in which $23.5 \%$ depends on paid attendants. Elderly depending among them on their son for any support of income were $90 \%$ and $90.2 \%$ of the study subjects lived with their family in joint family system while $9.8 \%$ lived among them. Out of all participants $75.5 \%$ have the decision power. Conclusion: The risk of diabetes, hypertension, and visual problems were more among the selected population of geriatrics.
\end{abstract}

Key words: $\quad$ Chronic Diseases, Geriatric, Health Issues, Lahore.

Article Citation: Mir A, Hassnain S, Khan A. Frequency of chronic diseases in elderly age group. Professional Med J 2021; 28(8):1120-1125. https://doi.org/10.29309/TPMJ/2021.28.08.5788

\section{INTRODUCTION}

The world is ageing rapidly. It presents as a great challenge to the increased demand for long term care along with primary health care. The societies which invest in healthy ageing can enable individuals to live healthy for a longer period. ${ }^{1}$ The older population proportion has been increasing from $8 \%$ to $11 \%$ from 1950 to 2007 and expected to rise by $22 \%$ in $2050 .{ }^{2}$ Almost $60 \%$ of this elderly population is living in the developing world. This value will increase to $70 \%$ by the year $2020 .^{3}$ Pakistan has a $7 \%$ population above the age of 60 years, which amounts to 11.6 million people. ${ }^{4}$ In Pakistan, there is no separate system for the health care of the elderly population. The older individuals require high demand for healthcare. ${ }^{2}$ but the increase in their proportion is a challenge to the health care system. ${ }^{5}$ They find it difficult to avail healthcare as per need. This problem is more pronounced in developing countries where financial issues are also present.

Due to improvement in life expectancy there is an abrupt rise in geriatric population. ${ }^{6}$ This age group is most susceptible to problems involving malnutrition and immobility ${ }^{7}$, thus demanding more attention. As of $2013,7 \%$ of the total population of Pakistan is above the age of 60 years, which amounts to 11.6 million people. It is estimated that this number will climb upwards to 43.3 million by 2050 when the geriatric fraction of the population will be at $16 \% .{ }^{4}$ since the numbers indicate a large rise in the number of elderly people, a concurrent improvement and expansion of health care services should be provided. However, in Pakistan no separate system exists for the health care of the elderly population. ${ }^{8}$ So the present healthcare system should allow older people better accessibility and availability of health care centers in Pakistan. Healthcare utilization services in Punjab, Pakistan reported that $20 \%$ elderly utilized services at the primary level whereas it was $25 \%$ at secondary health care facilities. ${ }^{9}$ -

The elder age group is facing a large number of 
problems and majority of them is dissatisfied with the available health care services. The dearth of geriatric care in Pakistan is evident by the fact that there are no specialized health care facilities available for the elderly. There are no training programs in geriatrics for specialization.

The traditional joint family system is also shifting towards nuclear family system, which is leading to many psychological issues in elderly. ${ }^{10}$ The geriatric population is affected by multiple health problems, for which there is dire need to highlight the medical and socioeconomic problems that are being faced by the elderly people. The purpose of this study is to identify the health needs of an aging population and to develop a comprehensive plan to improve the aspects of the life of older in the community.

\section{OBJECTIVE}

The aim of this study was to present sociodemographic characteristics and health seeking behavior of elderly and to determine frequency of chronic diseases in elderly population of a periurban community in Lahore, Pakistan.

\section{MATERIAL \& METHODS}

A cross sectional, house to house survey was conducted by using Random Walk and Quota Sampling, which is a type of non-probability sampling targeting the individuals of 65 years or older. A team of eleven medical students from fourth year MBBS of Fatima Memorial College of Medicine \& Dentistry, Lahore participated in the collection of data after being trained to fill survey questionnaire. The study was conducted at Eden homes Thokar Niaz Baig because of its peri-urban location and easy accessibility, In this technique the students had been asked to begin the interview process at some random geographic point in the Eden homes Thokar Niaz Baig and had been asked to follow a specified path of travel to select the house holds to interview such as that mention in the inclusion criteria. In this way each household qualifying the interview for the survey had been included until a predetermined quota had been reached. A total of 163 respondents were interviewed using pretested structured questionnaire after informed consent. Sample size was calculated using WHO calculator based on the proportion of elderly population in Pakistan. Original sample calculated was 100 but during data collection 163 individuals were interviewed to avoid non-response rate. Ethical approval through IRB of $\mathrm{FMH}$ was taken. $(\mathrm{FMH}-$ 03-2017-IRB-234-M)

Both males and females above the age of 60 years were surveyed. People below 60 years and patients of depression, dementia or Alzheimer's disease were excluded. The survey questionnaire obtained information on variables like age, gender, marital status, income, educational level, chronic illnesses, living status, daily physical activity and regular activities.

Individuals who gave history of high blood pressure, diagnosis of hypertension by health care provider and use of antihypertensive medications were recorded as hypertensive.

Individuals who gave history of diagnosis of diabetes by health care provider and were using hypoglycemic agents were recorded to be diabetics.

Individuals who were unable to count fingers at a distance of 3 meter were considered as visually impaired.

The data was analyzed using soft-ware statistical package of social sciences (SPSS v22). Frequencies were calculated for the variables and chi square test was used to determine association between the different variables.

\section{RESULTS}

Mean age of the elderly population was found out to be $69+7.1$ years. Out of them, $63.8 \%$ were males and $36.2 \%$ were females. The marital status in our sample population were found to be $76.1 \%$ as married, $1.2 \%$ unmarried, $20.9 \%$ widow and $1.8 \%$ were divorced. The $66.9 \%$ of old age group were literate whereas $33.1 \%$ were illiterate. In our sample $38 \%$ of the old population was dependent for finances whereas $61.9 \%$ were independent and the sources were pension (42.6\%), rent of any property (12.9\%), earn themselves (39.6\%) 
and $4.9 \%$ had other sources. (Table-I)

Mean age is $69+7.1$ years.

\begin{tabular}{|l|c|c|}
\hline $\begin{array}{c}\text { Socio-Demographic } \\
\text { Profile }\end{array}$ & Frequency & Percentage \% \\
\hline Gender & & \\
\hline Male & 104 & 63.8 \\
\hline Female & 59 & 36.2 \\
\hline Total & 163 & 100 \\
\hline Marital Status & & \\
\hline Married & 124 & 76.1 \\
\hline Unmarried & 2 & 1.2 \\
\hline Widow & 64 & 20.9 \\
\hline Divorced & 3 & 1.8 \\
\hline Total & 163 & 100 \\
\hline Education & & \\
\hline Illiterate & 54 & 33.1 \\
\hline Undergraduate & 71 & 43.6 \\
\hline Postgraduate & 163 & 23.3 \\
\hline Total & & 100 \\
\hline Source of income & & \\
\hline Dependent & 56 & \\
\hline Son & 0 & 90.3 \\
\hline Daughter & 6 & 0 \\
\hline Any other & 62 & 9.7 \\
\hline Total & & 100 \\
\hline Independent & 43 & 42.6 \\
\hline Pension & 13 & 12.9 \\
\hline Rent & 501 & 39.6 \\
\hline Earn & & 100 \\
\hline Other source & & \\
\hline Total & & \\
\hline & & \\
\hline
\end{tabular}

Table-I Socio-demographic profile.

\begin{tabular}{|l|c|c|}
\hline \multicolumn{1}{|c|}{ Activity } & Frequency & Percentage \\
\hline Independent & 146 & 89.6 \\
\hline Dependent & 17 & 10.4 \\
\hline Family & 13 & 76.5 \\
\hline Paid attendant & 4 & 23.5 \\
\hline Total & 163 & 100 \\
\hline $\begin{array}{l}\text { Individuals going for } \\
\text { daily walk }\end{array}$ & Frequency & Percentage \\
\hline Yes & 82 & 50.3 \\
\hline Less than 30 minutes & 20 & 24.4 \\
\hline 30 minutes & 32 & 39.0 \\
\hline 1 hour & 26 & 31.8 \\
\hline More than 1 hour & 04 & 4.8 \\
\hline No & 81 & 49.7 \\
\hline Total & 163 & 100 \\
\hline
\end{tabular}

Table-II. Physical activity.

\begin{tabular}{|l|c|c|}
\hline Individuals living with family & $\begin{array}{c}\text { Fre- } \\
\text { quency }\end{array}$ & $\begin{array}{c}\text { Per- } \\
\text { centage }\end{array}$ \\
\hline Yes & 147 & 90.2 \\
\hline Go for outing with family & 94 & 64 \\
\hline Have peaceful environment at home & 135 & 92 \\
\hline Have decision making power at home & 111 & 75.5 \\
\hline No & 16 & 9.8 \\
\hline Total & 163 & 100 \\
\hline \multicolumn{2}{|r|}{ Table-III. Behavior assessment. } \\
\hline
\end{tabular}

$89.6 \%$ of the individuals were independent in their physical activity whereas $10.4 \%$ were dependent for their activity. $50.3 \%$ walks daily out of which $95.2 \%$ walk minimally for one hour and $4.8 \%$ of them walk for more than one hour. (Table-II)

Elderly living with their families were $90.2 \%$, out of which $64 \%$ went for outing with their family, $92 \%$ had peaceful environment at their home and $75.5 \%$ do have the decision power. (Table-III)

The most commonly chronic ailments reported by these elderly were Hypertension 69.3\%, Diabetes $51.50 \%$, visual problem $52 \%$ and hearing issues $27 \%$.

The regular activities of this elderly group are mostly religious $61.4 \%$, followed by socialization $55 \%$, watching television $47.3 \%$ and reading $36.3 \%$.

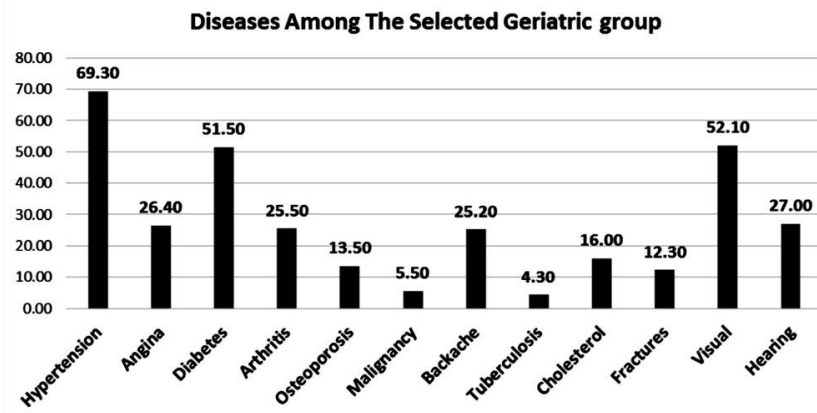

Figure-1. Percentages of the Diseases among geriatric population selected for the study.

\section{DISCUSSION}

The health of individuals and communities are affected by many factors and it is arbitrated by their surroundings and circumstances. ${ }^{11}$ The major determinants of health status of the elderly population in Lahore found in this study were 
chronic diseases, functional limitations and their regular activities. Among the individuals interviewed 104(63.8\%) were male while $59(36.2 \%)$ were females and male to female ratio was $1.7: 1$. In a study from Italy this ratio was $0.9:{ }^{12}$ while in a study from India this ratio was $1: 1 .{ }^{13}$ Education plays a significant role in all the aspects of life. The occupation, income and lifestyle all are affected by education. In our survey, 54 (33.1\%) individuals were illiterate, 71 (43.6\%) were undergraduate and 38 (23.3\%) were postgraduate. Literacy rate was higher in males $(76 \%)$ and lower in females $(50.8 \%)$, this was consistent with another study conducted in Karachi where (70.5\%) were found to be lliterate. ${ }^{14}$

Many are unable to work and need support from family. Out of 163 individuals 62(38\%) were financially dependent and $101(62 \%)$ were independent. Among the dependents, majority of them depend financially on their sons 56(90.3\%). A local study, conducted in Jakarta, also showed that majority of the elders (83.3\%) were supported by their sons ${ }^{15}$ while this is also consistent with an international study conducted in India that showed $98 \%$ of the dependent elderly were supported by their children. ${ }^{16}$ In the structure of our society, males are expected to earn and provide for their families.

Family has a great impact on the life of an individual. Family support is especially required at the extreme of ages when the person is not able to do all of their activities independently. In our society the joint family system is more prevalent as compared to nuclear system and old homes, which are not considered respectable. Due to these norms of the society, most of the older individuals in our community live with their families irrespective of their source of income. In our study 147 (90.2\%) of the individuals were living with their families and 16(9.8\%) were living alone. These results are similar to a study conducted internationally where majority of elderly were living with their family. ${ }^{14}$

Most of the elderly become debilitated due to the chronic illnesses associated with old age. Most prevalent diseases in our data were found to be hypertension $69.3 \%$ and diabetes $51.50 \%$ this is consistent with another study of geriatric individuals conducted internationally. ${ }^{14}$ These finding are similar to another study conducted internationally. ${ }^{17}$ In our data almost two third of the elders were suffering from hypertension and this finding is consistent with a study conducted in Ethiopia. ${ }^{18}$ Also more than $50 \%$ of the elders were suffering from more than one chronic disease also shown by another study of India. ${ }^{13}$ Communicable diseases are less prevalent in this age group as compared to non-communicable diseases. -

Diabetes is of major concern especially in developing countries like Pakistan. WHO data of 2016 showed that 422 million people were suffering from diabetes and majority of them are present in developing countries. ${ }^{11}$ The prevalence of diabetes in our data was $51.5 \%$ which means every second elder was suffering from diabetes. This high prevalence can be due to the fact that we collected data from urban community and they have sedentary life style, thus increase rise of type 2 diabetes. In another study conducted in population of Uttarakhand the prevalence of diabetes was low (36\%). ${ }^{19}$

Visual problems are very common in this age group. In our data visual problems found to be $52 \%$ while in a study conducted internationally $51.7 \%$ elders were suffering from visual problems. ${ }^{20}$

Chronic diseases especially the one that limits mobility leads to decreased physical activity. In our study we found that $146(89.6 \%)$ elders were independent in their physical activities $17(10.4 \%)$ were dependent. These results are consistent with a study conducted in Bangalore, Karnataka, India $75.8 \%$ were able to cope with daily physical activities than $24.2 \%$ who had decreased activities of daily living. ${ }^{21}$

In this study the regular activities include offering prayers $61.4 \%$, socializing $55 \%$, reading $36.3 \%$ and watching television $47.3 \%$ and these results are consistent with the study conducted in Agha Khan Hospital, Karachi. ${ }^{14}$ As the geriatric population is on the rise it's important to address 
their health and other problems which may contribute in improving their quality of life.

\section{LIMITATIONS}

The study constitutes of small sample size and only peri-urban area is covered so it may have restricted the generalizability of our results.

\section{CONCLUSION}

This study supports the view on chronic diseases in old age as a complex issue. To prevent the consequences of chronic diseases and other limitations associated with old age related problems demands multicomponent interventions. Early recognition of problems leading to disability and activities of daily living (ADL) dependence should be one of essential components of such interventions.

\section{Copyright(C) 18 Nov, 2020}

\section{REFERENCES}

1. World Health Organization. (2020). Ageing and life course. [Online] Available at: https://www.who.int/ ageing/en/ [Accessed 13 Feb. 2020]

2. Ageing Report - United Nations. [Online] Available at: https://www.un.org/en/development/desa/population/ publications/pdf/ageing/WPA2015_Report.pdf [Accessed 08 Nov 2020].

3. United Nations World Population ageing 2019 [cited 2020 Nov 8]. Available from: https://www.un.org/en/ development/desa/population/publications/pdf/ageing/ WorldPopulationAgeing2019-Highlights.pdf

4. Helpage.org. (2020). Data on ageing | Resources | Help Age International. [online] Available at: https:// www.helpage.org/resources/ageing-data/ [Accessed 13 Feb. 2020].

5. Beard HP, Bloom DE. Towards a comprehensive public health response to population ageing. Lancet (London, England). 2015; 385(9968):658.

6. Mackenbach J, Garssen J. Renewed progress in life expectancy: The case of the Netherlands. International differences in mortality at older ages: Dimensions and sources 2010. National Academies Press (US).

7. Fávaro-Moreira NC, Krausch-Hofmann S, Matthys C. Risk factors for malnutrition in older adults: A systematic review of the literature based on longitudinal data. Advances in nutrition. 2016 May; $7(3): 507-22$.
8. Sabzwari SR, Azhar G. Ageing in Pakistan-a new challenge. Ageing International. 2011 Dec 1; 36(4):4237.

9. Apps.who.int. (2020). [online] Available at: http://apps. who.int/medicinedocs/documents/s17305e/s17305e. pdf [Accessed 13 Feb. 2020].

10. Qidwai W, Khushk IA, Allauddin S, Nanji K. Influence of elderly parent on family dynamics: Results of a survey from Karachi, Pakistan. World Family Medicine Journal: Incorporating the Middle East Journal of Family Medicine. 2017 Feb; 99(4100):1-7.

11. Who.int. (2020). WHO |. The determinants of health. [online] Available at: https://www.who.int/hia/evidence/ doh/en [Accessed 13 Feb. 2020].

12. Atella V, Piano Mortari A, Kopinska J. Trends in age $\square$ related disease burden and healthcare utilization. Aging cell. 2019 Feb; 18(1):e12861.

13. Reshmi PS, Al Hussaini SM, Bendigiri NA, Tenglikar SG. A cross sectional study on the health status of geraitric population. IJCMPH; 2017; 3(6):1477-80.

14. Song $\mathrm{Y}$, Zhang J. Living together with children and elderly: The impact of family structure on the consumption of migrants and residents in urban China. China Population and Development Studies. 2018 Jun 1; 2(2):186-203.

15. Riasmini NM, Sahar J, Supartini Y, Maryam RS. Independent family group model improving health status and quality of life of elderly in the community. Indian Journal of Public Health Research \& Development. 2019; 10(12):1930-4.

16. Eram U, Nawab T, Najam Khalique D. Study of morbidity pattern in geriatric population in rural areas of Aligarh. IJCTET; 2016 Nov; 2(06).

17. Cybulski M, Krajewska-Kułak E, Sowa P. Most common health problems of elderly in the opinion of health sciences students in Poland, Belarus and Greece. Progress in Health Sciences. 2016; 6(2):39-45.

18. Shukuri A, Tewelde T, Shaweno T. Prevalence of old age hypertension and associated factors among older adults in rural Ethiopia. Integrated Blood Pressure Control, 2019; 12:23.

19. Kapil U, Khandelwal R, Ramakrishnan L. Prevalence of hypertension, diabetes, and associated risk factors among geriatric population living in a high-altitude region of rural Uttarakhand, India. Journal of family medicine and primary care. $2018 \mathrm{Nov} ;$ 7(6):1527. 
20. Jaul E, Barron J. Age-related diseases and clinical and public health implications for the $\mathbf{8 5}$ years old and over population. Frontiers in public health. 2017 Dec 11; 5:335.
21. Kavya C, Santosh A. Geriatric health: assessment of nutritional status and functional ability of elderly living in rural area of Bangalore, Karnataka, India. IJCMPH; 2016; 3(12):3460-4.

\section{AUTHORSHIP AND CONTRIBUTION DECLARATION}

\begin{tabular}{|c|c|c|c|}
\hline Sr. \# & Author(s) Full Name & Contribution to the paper & Author(s) Signature \\
\hline 1 & Arslan Mir & $\begin{array}{l}\text { Synopsis development, Introduction, } \\
\text { Discussion. }\end{array}$ & \\
\hline 2 & Shamaila Hassnain & $\begin{array}{l}\text { Methodology, Results and overall } \\
\text { supervision. }\end{array}$ & \\
\hline 3 & Anas Khan & $\begin{array}{l}\text { Results, Figures, Conclusion, } \\
\text { Limitations, Data Collection. }\end{array}$ & $\sigma$ \\
\hline
\end{tabular}

